\title{
The role of RNA structure in translational regulation by L7Ae protein in archaea
}

\author{
LIN HUANG, SAIRA ASHRAF, and DAVID M.J. LILLEY \\ Cancer Research UK Nucleic Acid Structure Research Group, The University of Dundee, Dundee DD1 5EH, United Kingdom
}

\begin{abstract}
A recent study has shown that archaeal L7Ae binds to a putative k-turn structure in the $5^{\prime}$-leader of the mRNA of its structural gene to regulate translation. To function as a regulator, the RNA should be unstructured in the absence of protein, but it should adopt a k-turn-containing stem-loop on binding L7Ae. Sequence analysis of UTR sequences indicates that their k-turn elements will be unable to fold in the absence of L7Ae, and we have demonstrated this experimentally in solution using FRET for the Archaeoglobus fulgidus sequence. We have solved the X-ray crystal structure of the complex of the A. fulgidus RNA bound to its cognate L7Ae protein. The RNA adopts a standard k-turn conformation that is specifically recognized by the L7Ae protein, so stabilizing the stem-loop. In-line probing of the natural-sequence UTR shows that the RNA is unstructured in the absence of L7Ae binding, but folds on binding the protein such that the ribosome binding site is occluded. Thus, L7Ae regulates its own translation by switching the conformation of the RNA to alter accessibility.
\end{abstract}

Keywords: gene regulation; RNA structure; kink-turn; X-ray crystallography

\section{INTRODUCTION}

Riboregulation takes many forms. It can be mediated by small RNA molecules (noncoding regulatory RNA), metabolites (in the riboswitches) or proteins. A number of ribosomal proteins are subject to autoregulation; a good example is the binding of bacterial S15 protein to a specific structure within the $5^{\prime}$ region of its mRNA to repress translation (Serganov et al. 2003). L7Ae is an archaeal ribosomal protein that has attracted recent interest in terms of autoregulation (Daume et al. 2017). This is a member of a family of structure-selective RNA binding proteins that includes yeast $\mathrm{L} 30 \mathrm{e}$ and the human $15.5 \mathrm{~K}$ protein (Koonin et al. 1994; Watkins et al. 2000). These proteins fulfill a number of roles; they are important components in the large ribosomal subunit (Ban et al. 2000), box C/D (Kuhn et al. 2002; Szewczak et al. 2002; Watkins et al. 2002), and H/ACA (Rozhdestvensky et al. 2003; Hamma and Ferré-D'Amaré 2004; Li and Ye 2006) snoRNPs and U4 snRNA in the spliceosome cycle (Nottrott et al. 1999; Vidovic et al. 2000). In addition, they are components of U3 snoRNP (Marmier-Gourrier et al. 2003), telomerase (Pogacić et al. 2000), and RNaseP that is involved in tRNA 5 '-end processing (Cho et al. 2010). L7Ae-family proteins are thus essential in many cellular processes includ-

Corresponding author: d.m.j.lilley@dundee.ac.uk

Article is online at http://www.rnajournal.org/cgi/doi/10.1261/rna. 068510.118 . Freely available online through the RNA Open Access option. ing ribosome structure, spliceosome assembly and guided site-specific modification of RNA.

The L7Ae family of proteins selectively bind to a widespread structural motif in RNA called the kink turn (k-turn) (Klein et al. 2001), which has recently been reviewed in depth (Huang and Lilley 2018). The k-turn is a motif found in duplex RNA comprising a short (usually $3 \mathrm{nt}$ ) bulge followed by tandem trans-sugar-Hoogsteen $G: A$ base pairs. The RNA can adopt one of two conformations; either a relatively extended structure similar to a typical 3-nt bulge, or a tightly kinked structure where the helical axis includes an angle of $50^{\circ}$ (Goody et al. 2004). The kinked conformation requires juxtaposition of the two minor grooves, with formation of key cross-strand hydrogen bonds at the interface (Lescoute et al. 2005; Liu and Lilley 2007; Daldrop and Lilley 2013). The major groove is splayed open on the outer face of the RNA. The kinked structure of the k-turn requires stabilization that can be effected by a number of alternative processes. Some, but importantly not all, k-turns become stabilized on addition of metal ions (Goody et al. 2004; Liu and Lilley 2007). Whether or not a given k-turn folds in response to metal ions depends upon its sequence, and we have found that two sequence elements act as key determinants of this behavior (McPhee et al. 2014; Ashraf et al. 2017). Protein binding provides an alternative way to stabilize

(C) 2019 Huang et al. This article, published in RNA, is available under a Creative Commons License (Attribution 4.0 International), as described at http://creativecommons.org/licenses/by/4.0/. 
the folded k-turn. The great majority of k-turns can be stabilized by the binding of L7Ae-family proteins (Turner et al. 2005), which bind with very high affinity (Turner and Lilley 2008). Importantly, even those k-turns that do not fold on addition of metal ions generally fold on binding L7Ae (McPhee et al. 2014) or 15.5K (Huang et al. 2017) proteins. Examples of $\mathrm{k}$-turns that exhibit this behavior are the archaeal box C/D k-turns (Ashraf et al. 2017) and the human U4 snRNA k-turn (McPhee et al. 2014).

In a recent study, Randau and colleagues (Daume et al. 2017) obtained evidence pointing to an interesting new mechanism of genetic regulation in archaea, involving the interaction between L7Ae and the transcript of its structural gene. Using the archaeon Sulfolobus acidocaldarius, they performed a RIP-Seq analysis to provide the L7AeRNA interactome, and so identified over 100 RNA species that bind L7Ae in the cell, of which 59 were box C/D snoRNAs. This also included 32 mRNA species, one of which was the transcript of $17 a e$, the structural gene encoding L7Ae protein. Detailed analysis of the data indicated that the principal site of binding lay in the $5^{\prime}$-untranslated region (UTR) of the transcript, the sequence of which was consistent with the formation of a short stem-loop structure that contained a potential k-turn structure. The stem-loop overlapped with the ribosome binding site, suggesting a potential mechanism for translational regulation, and this was supported by reporter assays showing the down-regulation of translational in the presence of L7Ae. Daume et al. (2017) also found that potential k-turn-forming hairpin structures were a conserved feature in the 5'-UTR regions of archaeal genes encoding L7Ae.

This suggests a mechanism of gene regulation in which the RNA structure of the transcript plays a key role. It seems probable that the $5^{\prime}$-UTR sequence would be unstructured and accessible to the translation machinery until bound by L7Ae. Thereupon the k-turn would fold to stabilize the stem-loop that would occlude the ribosome binding site. In this work we have sought to test two structural aspects of this model. First, in the absence of L7Ae the RNA should not fold into the kinked conformation k-turn, but rather should behave like the archaeal box C/D k-turn that is unfolded in the presence of metal ions. Second, when present L7Ae should bind so that the k-turn folds and a standard L7Ae-k-turn complex is formed. We have found that both of these criteria are met for the Archaeoglobus fulgidus 17ae leader RNA, supporting the proposed regulatory mechanism.

\section{RESULTS}

\section{The predicted folding ability of k-turns in L7Ae gene UTRs}

The 5'-UTR regions of the 17 ae genes from six different archaeal species (first identified by Daume et al. 2017) are drawn in Figure 1 to show how each could potentially form a hairpin loop containing a k-turn structure. Each sequence can be drawn as a stem-loop containing a GAU bulge followed by tandem G:A and A:G base pairs. The nomenclature of sequence positions in the k-turn (Liu and Lilley 2007) is shown at the top of Figure 1. The polarity of the k-turn within the stem-loop is evenly divided such that three have the terminal loop on the C-helix and three on the NC-helix. In each case, the Shine-Dalgarno ribosome binding site (shaded in Fig. 1) is in very close proximity to the k-turn motif, although its position with respect to the k-turn varies from sequence to sequence.

In general, these stem-loop structures appear to be of low intrinsic stability, especially at the elevated temperatures at which many of these thermophilic organisms live. In all cases, the C-helix has a limited number of WatsonCrick base pairs, and some of the sequences have few Watson-Crick base pairs following the G:A base pairs. If the stem-loop structures do form, we can ask how readily might the k-turn fold into its tightly kinked conformation in

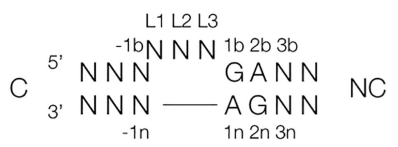

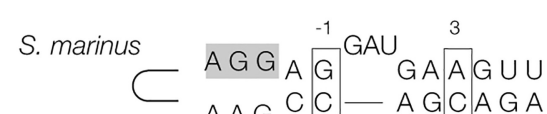

$$
\begin{aligned}
& \text { A. fulgidus } G A G_{C}{ }^{-1} \mathrm{CAU} G A \mathrm{~B}^{3} \cup G_{A} \\
& G A G G A-A G \cup A G U D
\end{aligned}
$$

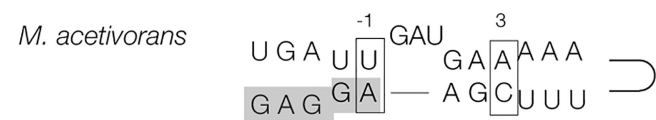

$$
\begin{aligned}
& \text { T. kodakarensis } \quad \mathrm{GAA}_{\mathrm{A}} \mathrm{C}_{\mathrm{C}}^{\mathrm{G}} \mathrm{GAU} \mathrm{GA} \mathrm{B}_{\mathrm{G}}^{\mathrm{G}} \mathrm{G} \cup \cup
\end{aligned}
$$

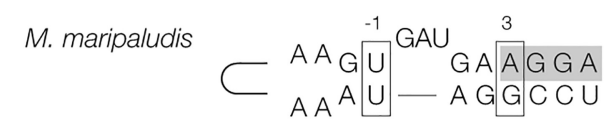

$$
\begin{aligned}
& \text { S. acidocaldarius } \mathrm{G}^{A A G} A \mathbb{G}^{-1} \mathrm{GAU},{ }^{3} \mathrm{~A} A \mathrm{AC} \\
& A_{A A A} G-A G \cup G C G
\end{aligned}
$$

FIGURE 1. Potential k-turn sequences occurring in the $5^{\prime}$-UTR sequences of the mRNA of archaeal 17 ae genes. Each sequence is drawn in the form of a hairpin loop containing a putative k-turn structure, with the critical $-1 \mathrm{~b}:-1 \mathrm{n}$ and $3 \mathrm{~b}: 3 \mathrm{n}$ sequences boxed. The dependence of ion-dependent folding on the $3 \mathrm{~b}: 3 \mathrm{n}$ sequence is summarized in Supplemental Figure S1. The Shine-Dalgarno (ribosome binding site) sequences are shaded. The locations of the terminal loops are indicated schematically. The nomenclature of sequence positions for a standard k-turn is shown at the top. Sequence information was taken from Daume et al. (2017). 
the absence of protein binding. We have previously studied this in some depth (McPhee et al. 2014; Ashraf et al. 2017), and have identified two critical sequence elements that determine the ability of a k-turn to fold in response to the presence of metal ions.

1. The $3 b: 3 n$ sequence. We showed that the $3 b: 3 n$ sequence that follows the tandem $G: A$ and $A: G$ base pairs in the well-characterized standard k-turn Kt-7 has a major influence on its ion-induced folding (McPhee et al. 2014). We noted that Watson-Crick base pairs prevent folding, while $3 b=C$ or $3 n=G$ conferred ion-induced folding. We have previously presented crystallographic evidence for the origin of the $3 n=G$ rule, showing that the guanine $\mathrm{O} 6$ atom is directly bound to a magnesium ion in the major groove (McPhee et al. 2014). For ease of reference, the sequence-dependent data are summarized in Supplemental Figure S1.

2. The $-1 b:-1 n$ sequence. Recently we have found that the $-1 b:-1 n$ sequence that precedes the bulge can have a strong influence on ion-induced folding (Ashraf et al. 2017). Systematic comparison of the folding of $\mathrm{Kt}-7$ and the box C/D k-turns showed that $-1 \mathrm{~b}:-1 \mathrm{n}=$ $\mathrm{C}: \mathrm{G}$ confers folding in metal ions, while inversion to $-1 \mathrm{~b}:-1 \mathrm{n}=\mathrm{G}:$ C prevents folding under the same conditions. The great majority of natural k-turns have $-1 \mathrm{~b}$ : $-1 \mathrm{n}=\mathrm{C}: \mathrm{G}$, and $-1 \mathrm{~b}:-1 \mathrm{n}=\mathrm{G}: \mathrm{C}$ is quite rare. No systematic study has been made of the folding properties resulting from all possible sequences at the $-1 b:-1 n$ position, but we have found that $-1 b:-1 n=C: A$ prevents ion-induced folding of Kt-7 (Supplemental Fig. S2).

These rules appear to apply generally for all k-turns studied. Importantly, every k-turn that has been analyzed, irrespective of the $3 b: 3 n$ or $-1 b:-1 n$ sequences, undergoes folding into the kinked conformation on addition of L7Ae protein (McPhee et al. 2014; Ashraf et al. 2017).

Insofar as possible we have applied the above rules to the 17ae URT k-turn sequences. With a single exception (M. maripaludis), none of the elements has $3 b=C$ or $3 n=G$, and with that exception none is expected to fold well in response to metal ions. In addition, none of the six sequences has $-1 b:-1 n=C: G$, and two have $G: C$ and one has $C: A$. The remaining three have $-1 b:-1 n$ sequences whose folding properties have not been studied. Taken together, it is probable that all the sequences are unable to fold into a stable k-turn conformation in response to the addition of metal ions.

\section{Analysis of the folding of the I7ae gene k-turn from Archaeoglobus fulgidus}

If a k-turn is to behave as a translational switch to regulate $\mathrm{L} 7 \mathrm{Ae}$ protein synthesis, it would require two characteris- tics. It should not fold into a stable k-turn conformation in the absence of the protein, despite the presence of metal ions, but it should bind L7Ae protein and thereupon fold into the kinked conformation. We chose the $A$. fulgidus 17ae UTR to explore this question. It has $3 \mathrm{~b}: 3 \mathrm{n}=\mathrm{A}: \mathrm{U}$, and $-1 b:-1 n=C: A$, both of which prevent ion-induced folding in Kt-7 (Supplemental Fig. S2; McPhee et al. 2014).

We studied the folding of this element using fluorescence resonance energy transfer (FRET). For this purpose we synthesized a dsRNA containing the central k-turn, extending the natural sequence to have $\mathrm{C}$ and $\mathrm{NC}$ arms of 12 and $13 \mathrm{bp}$, respectively (Fig. 2, top). The $5^{\prime}$ termini were labeled with fluorescein donor and Cy3 acceptor fluorophores. Fluorescence emission spectra were recorded in the steady state, and FRET efficiency $\left(E_{\mathrm{FRET}}\right)$ calculated using the acceptor normalization method (Clegg 1992). If the RNA is kinked by the folding of the k-turn, the separation between the fluorophores will decrease and consequently $E_{\text {FRET will increase. }}$

The fluorescent RNA was titrated with either $\mathrm{Mg}^{2+}$ ions or A. fulgidus $L 7 A$ e protein (AfL7Ae), and $E_{\mathrm{FRET}}$ has been plotted as a function of ion or protein concentration (Fig. 2). It is immediately apparent that the two sets of data are quite different in character. The value of $E_{\text {FRET }}$ as a function of

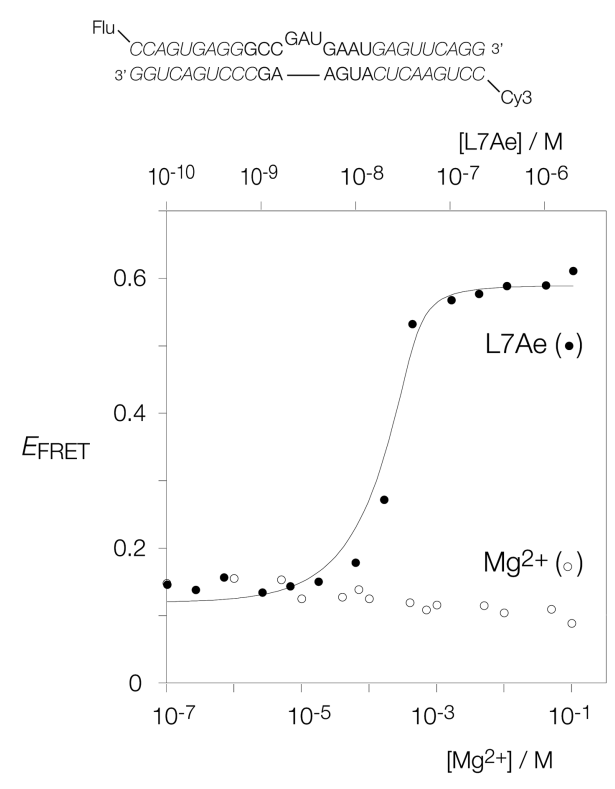

FIGURE 2. Folding of the A. fulgidus $17 a$ ae $5^{\prime}$-UTR k-turn in response to $\mathrm{Mg}^{2+}$ ions and L7Ae studied by FRET. The RNA shown at the top was synthesized with 5 ' fluorescein donor and Cy-3 acceptor. The nucleotides written in italic extend the $A$. fulgidus sequence to make a duplex suitable for the FRET experiments. A solution of $20 \mathrm{nM}$ fluorophore-labeled RNA was titrated with either $\mathrm{Mg}^{2+}$ ions (lower concentration scale) or L7Ae protein (upper concentration scale) and $E_{F R E T}$ measured in the steady state. $E_{F R E T}$ is plotted as a function of $\mathrm{Mg}^{2+}$ ions (open circles) and L7Ae protein (closed circles). The RNA clearly fails to fold in response to the addition of the metal ions. However, addition of L7Ae results in a structural transition, and the data have been fitted (line) to Equation 1. 
$\mathrm{Mg}^{2+}$ concentration (open circles) remains at a low value $(<0.18)$ across the whole range of ionic concentration. In contrast, addition of L7Ae protein (closed circles) results in a marked increase in $E_{\mathrm{FRET}}$ at stoichiometric concentration, reaching a plateau value of 0.6 . This is the standard behavior of a k-turn that folds on binding a member of the L7Ae family of proteins (Turner et al. 2005; Turner and Lilley 2008; Huang et al. 2017). Thus, the A. fulgidus 17ae UTR folds in a manner consistent with the formation of a normal k-turn in response to the binding of L7Ae, but is unable to fold stably on addition of metal ions alone.

\section{Crystal structure of $A$. fulgidus L7Ae bound to its cognate UTR k-turn}

The change in $E_{F R E T}$ on binding AfL7Ae to the A. fulgidus I7ae UTR is consistent with the formation of a folded k-turn at the binding site. This was explored further by X-ray crystallography. We synthesized the RNA shown in Figure 3 (top) that comprises a twofold symmetrical duplex containing two k-turns. This required just two sequence changes from the natural UTR sequence, in the $-3 n$ and $5 n$ positions (highlighted in blue). The RNA was co-crystallized with $A f L 7 A e$, and the structure was solved at a resolution of $3.09 \AA$ by molecular replacement using the structure of Afl7Ae bound to Kt-7 (PDB ID 4BWO) (Huang and Lilley 2013).

In the crystal lattice, three two-kturn units adopted a triangular arrangement, with six $\mathrm{L} 7 \mathrm{Ae}$ molecules bound to six k-turns (Supplemental Fig. S3). The structure of a single kturn bound to one molecule of Afl7Ae is shown in Figure 3 and the RNA structure is shown in detail in Figure 4. The overall structure of the complex (Fig. 3A) is closely similar to that of other $\mathrm{L} 7 \mathrm{Ae}$ complexes, such as those with Kt-7 (Huang and Lilley 2013), box C/D (Moore et al. 2004), and U4 (Vidovic et al. 2000) k-turns. L7Ae places its recognition $\alpha$-helix in the widened major groove that is splayed around the outside of the k-turn, and places a hydrophobic loop over the L2 nucleobase (Fig. 3B). The recognition helix makes the usual nonspecific interactions with the RNA (using the sidechains of K37 and R41) and specific hydrogen-bonding interactions with the $\mathrm{G} 1 \mathrm{~b}$ and G2n nucleobases of the tandem G:A base pairs (using E34 and N33, respectively). In addition, the $\mathrm{O} 6$ atom of $\mathrm{G} 1 \mathrm{~b}$ is located on the axis of the $\alpha$-helix where its partial negative charge makes an electrostatic interaction with the positive pole of the helix dipole moment.

In the complex, the RNA is folded into a standard k-turn conformation (Fig. 4). L1 is stacked on the $-1 b:-1 n$ base pair, and $L 2$ adopts a syn conformation to stack on the 1b:1n G:A base pair (Fig. 4A). Both G:A base pairs are trans-sugar-Hoogsteen pairs, and the adenine nucleobases accept the usual cross-strand hydrogen bonds. L1 O2' donates a hydrogen bond to $A 1 n$ N1, while $A-1 n$ O2' donates one to A2b N3 (Fig. 4B). Thus the k-turn

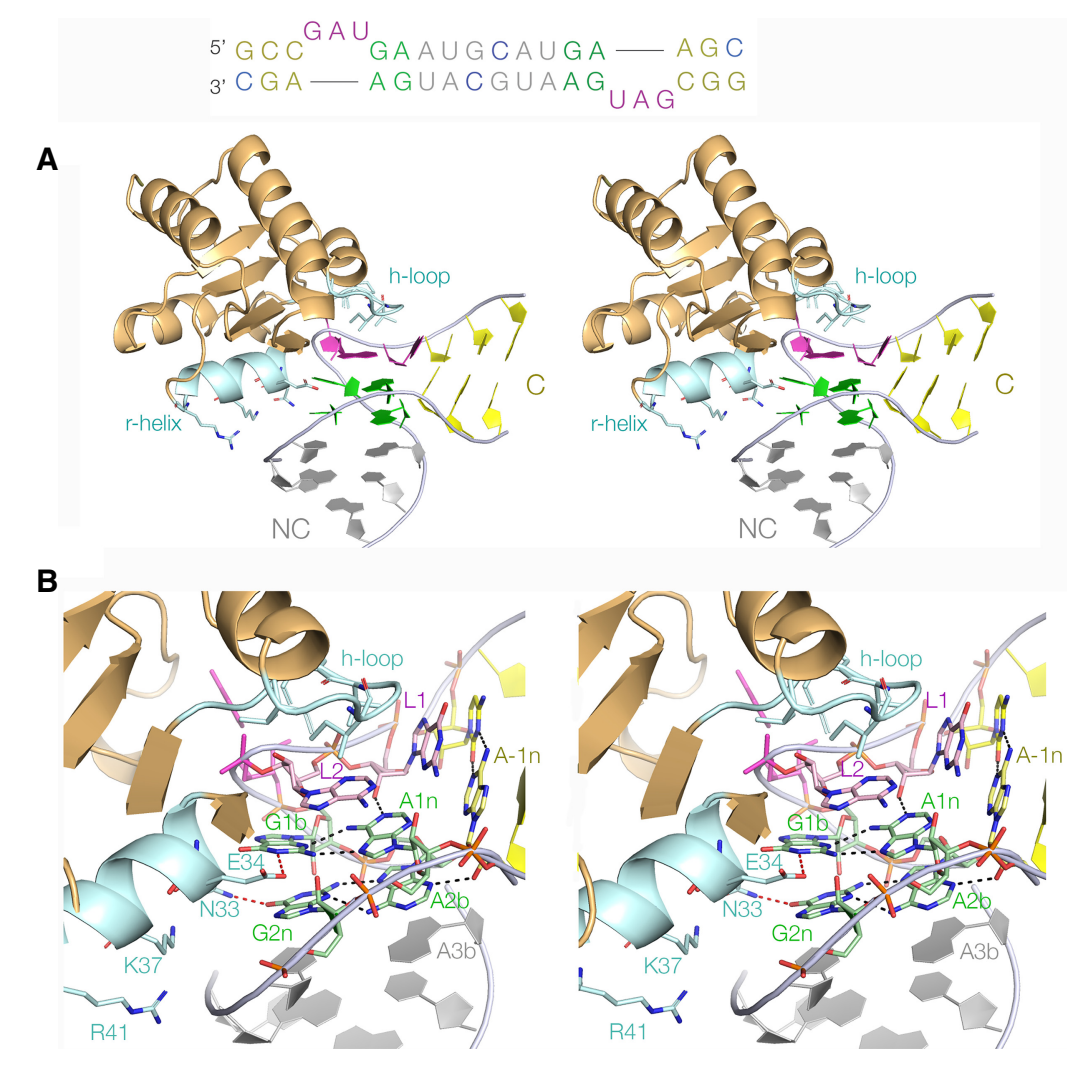

FIGURE 3. The structure of the A. fulgidus L7Ae-RNA complex. X-ray crystal structure of Afl7Ae bound to the k-turn of the 17ae 5'-UTR k-turn. The RNA (sequence shown at top) contains two copies of the potential k-turn related by twofold rotational symmetry. The two nucleotide changes were made to create full base-pairing at $-3 n$ and $5 n$; these are highlighted in blue. Our standard color-coding has been used for the k-turn, with the G:A base pairs green, the $\mathrm{C}$ and $\mathrm{NC}$ helices gray and yellow, respectively, and the loop magenta. This color scheme is also used in the structural images. The molecular graphics are shown as parallel-eye stereoscopic images. (A) The overall structure of the complex. The L7Ae protein is shown in cartoon form colored orange apart from the recognition helix and hydrophobic loop that are highlighted in cyan. Important amino acid side chains are shown in stick form. (B) The protein-RNA interactions in greater detail. The recognition helix ( $r$-helix) is located in the widened major groove on the outer face of the k-turn, and the side chains of E34 and N33 are hydrogen bonded to the nucleobases of G1b and G2n, respectively. The hydrophobic loop ( $h$-loop) sits over the $L 2, L 1$ region of the k-turn. 


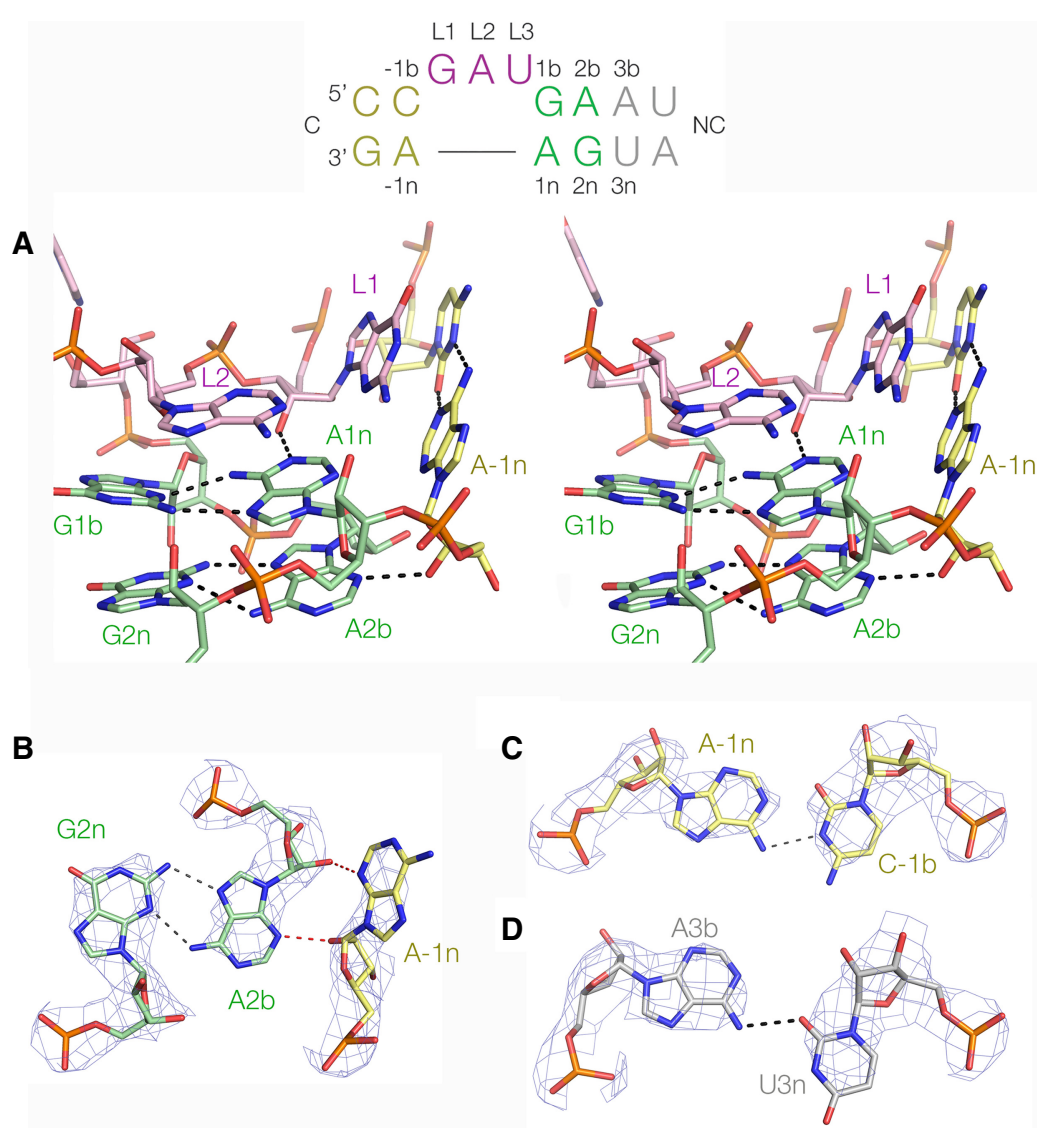

FIGURE 4. The structure of the A. fulgidus 5'-UTR k-turn in complex with L7Ae. The sequence and nucleotide nomenclature for the k-turn is shown at the top. (A) A parallel-eye stereoscopic image of the core of the k-turn. The RNA adopts the conformation of a standard, simple k-turn with two trans-sugar-Hoogsteen G:A base pairs and cross-strand hydrogen bonds from the O2' groups of $L 1$ and $-1 n$ ribose to the nucleobases of $A 1 n$ and $A 2 b$, respectively. $B$ through $D$ show details from the structure with electron density from the $2 F_{o}-F_{c}$ map contoured at 2.5 $\sigma$. (B) The $A 2 b: G 2 n$ base pair and its interaction with $A-1 n$. A-1n N3 accepts a hydrogen bond from $A 2 b$ O2', and its O2' donates one to $A 2 b$ N3. The A2b:G2n base pair is associated by two hydrogen bonds. This k-turn is therefore a standard N3 structure (Daldrop and Lilley 2013). (C) The C-1b:A-1n base pair. This forms a cis base pair associated by a single hydrogen bond from A-1n N6 to C-1b N3. (D) The A3b:U3n base pair. This forms a trans base pair associated by a single hydrogen bond from $A 3 b \mathrm{~N} 6$ to U3n O2.

\section{L7Ae-induced structural change in the A. fulgidus I7ae 5'-UTR stem-loop}

In addition to spectroscopic and crystallographic studies, we have investigated the structural change in the k-turn-carrying stem-loop structure formed by the A. fulgidus 17ae 5'-UTR stem-loop RNA using chemical probing. For this experiment, the natural sequence of the $5^{\prime}$-UTR was used without any changes, and the results compared with those from a modified sequence in which the $1 b$ and $2 \mathrm{~b}$ nt were exchanged for $\mathrm{C}$ and $G$ respectively to prevent adoption of the k-turn conformation. These were studied by in-line probing (Soukup and Breaker 1999) as a function of added L7Ae concentration. 5'-Cy5-labeled RNA was incubated at room temperature in $50 \mathrm{mM}$ Tris$\mathrm{HCl}\left(\mathrm{pH}\right.$ 8.3), $20 \mathrm{mM} \mathrm{MgCl}_{2}$, and 100 $\mathrm{mM} \mathrm{KCl}$ for $40 \mathrm{~h}$. Under these conditions, each phosphodiester linkage may be cleaved as a result of nucleophilic attack by its adjacent 2 '-hydroxyl group if it can adopt the required in-line geometry. The products of cleavage are separated by electrophoresis in a denaturing polyacrylamide gel. In general, the extent of cleavage at a given position (i.e., the intensity of the product bands) is a measure of the flexibility of the RNA at that point, allowing it to sample the in-line conformation. The results are shown in Figure 5, with the regions of reactivity and protection shown on the schematic (left).

adopts the N3 conformation (Daldrop and Lilley 2013), and the $A 2 b: G 2 n$ base pair is associated by two hydrogen bonds. Parenthetically, this provides experimental confirmation of our previous prediction that k-turns with $3 b: 3 n=A: U$ would adopt the N3 conformation (see Supplemental Fig. S1; Huang et al. 2016).

The 17ae UTR k-turn contains some sequence elements not previously present in k-turn structures. The A-1b:C$1 \mathrm{n}$ forms a cis base pair associated by a single hydrogen bond from A-1n N6 to C-1b N2 (Fig. 4C). The A:U base pair at the $3 \mathrm{~b}: 3 \mathrm{n}$ position is not a standard Watson-Crick pair; rather it adopts a trans conformation with a single hydrogen bond from A3b N6 to U3n O2 (Fig. 4D). The 4b:4n base pair is a standard cis-Watson-Crick pair.
In the absence of L7Ae protein, both wild-type and mutant RNAs exhibited uniform cleavage along their length, consistent with a largely single-stranded character. However, on addition of $A$. fulgidus L7Ae to the unmodified UTR sequence, the section corresponding to the stem regions became protected, and that corresponding to the loop exhibited enhanced reactivity. In contrast, the mutant sequence gave a rather different pattern of bands indicative of a different mode of binding and not consistent with the same stem-loop formation. We know from earlier work that at higher L7Ae concentration nonspecific binding can occur, that does not result in the standard k-turn conformation. From a functional point of view it is apparent that the ribosome binding site is reactive (i.e., 


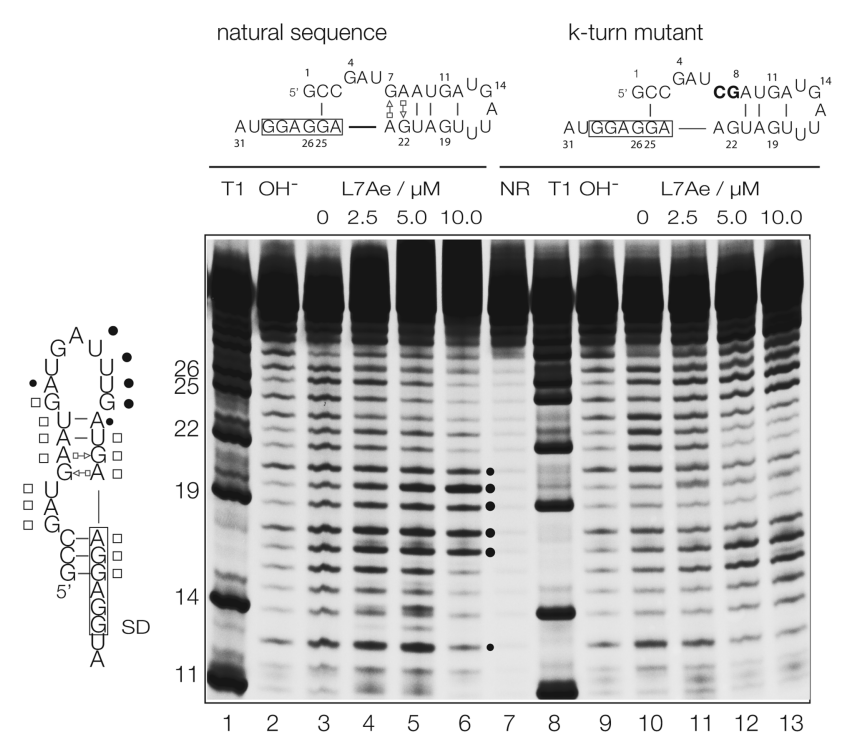

FIGURE 5. Analysis of conformational change in the A. fulgidus 5'-UTR RNA induced by the binding of AfL7Ae protein using in-line probing (Soukup and Breaker 1999). The sequences of the two RNA species studied are shown at the top, drawn in their potential stemloop conformations. The boxed regions are the ribosome binding site. The mutant sequence (right) has two sequence changes (highlighted in bold) in the G:A base pairs that will prevent k-turn formation. Tracks 1 and 8 contain RNA cleaved by T1 nuclease that cuts $3^{\prime}$ to $G$ nucleotides to provide a reference frame (sequence positions shown on the left). Tracks 2 and 9 contain natural-sequence RNA subject to hydroxide cleavage to generate cleavage through the RNA. Track 7 contains RNA not subjected to any degradation procedure, i.e., fulllength RNA. Tracks 3 through 6 and 10 through 13 contain the results of in-line probing in the presence of $0,2.5,5$, and $10 \mu \mathrm{M}$ Afl7Ae for natural and mutant RNA, respectively. The black circles drawn on the fluorogram denote positions of reactivity in the natural $5^{\prime}$-UTR RNA in the presence of L7Ae. The schematic on the left shows the sequence of the natural 5'-UTR drawn in its stem-loop conformation. Filled circles denote positions of reactivity and open squares denote positions of protection, both in the presence of L7Ae.

flexible) in the mutant, but becomes protected in the L7Ae complex for the natural sequence. These results are consistent with the formation of the stem-loop structure in the natural 5'-UTR that is stabilized by binding of L7Ae to the k-turn structure, with a resulting occlusion of the ribosome binding site.

\section{DISCUSSION}

We have shown that $A$. fulgidus L7Ae binds to the $5^{\prime}$-UTR of the mRNA of its structural gene, stabilizing the standard k-turn conformation that should occlude the ribosome binding site. In the absence of L7Ae protein, the stemloop structure should be very unstable, as we demonstrate by in-line probing. This will be accentuated at the elevated temperature at which this thermophilic archaeon lives. Under these conditions, the equilibrium between unstructured RNA and the stem-loop will be heavily biased to- ward the open structure. Previous single-molecule studies from our laboratory are consistent with protein stabilization of k-turn structure occurring by conformational selection (Wang et al. 2012), and our FRET studies show that the k-turn is largely unfolded in the absence of L7Ae protein. We conclude that in the absence of protein the RNA is predominantly single-stranded, and it requires binding of L7Ae to the k-turn structure to stabilize the stem-loop structure. Until this happens the RNA should be available to ribosome binding and thus the RNA is translated. On binding L7Ae, the stem-loop becomes stable and the ribosome binding site occluded. These are exactly the characteristics required for a translational OFF switch that would self-regulate synthesis of the L7Ae protein, shown in cartoon form in Figure 6.

Daume et al. (2017) showed that elements that could potentially form k-turn structures exist in the $5^{\prime}$-UTRs of I7ae genes of a wide variety of archaea, and used reporter constructs to demonstrate regulation of translation in that from S. acidocaldarius. Application of sequence rules indicates the majority (probably all) will be unable to form k-turn structures in the absence of protein, so k-turn formation unaided by L7Ae binding cannot stabilize the stemloop structure and translation can initiate until the k-turn elements are bound and folded by L7Ae. These elements were identified in both Crenarchaeota (e.g., S. acidocaldarius) and Euryarchaeota (e.g., A. fulgidus) that diverged very early in the evolution of life (>3 Gy ago) (Battistuzzi et al. 2004), so this regulatory mechanism is likely to be ancient. This extends further, into the eukaryota. In budding yeast, the $5^{\prime}$-UTR of the structural gene for L30e, another member of the L7Ae family, has a k-turn structure (Mao et al. 1999; Chao and Williamson 2004). This too has been shown to be involved in the self-regulation of L30e translation (Dabeva and Warner 1993). In addition, the motif incorporates a splice site, and evidence suggests that it is involved in the regulation of splicing (Eng and Warner 1991). It is therefore probable that the alteration of RNA

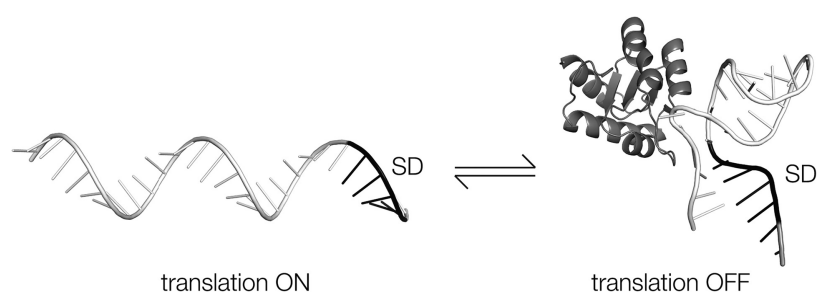

FIGURE 6. Cartoon showing the probable mechanism of regulation of translation by the binding of L7Ae to the $5^{\prime}$-UTR leader sequence. In the absence of the protein, the RNA is unstructured and the ShineDalgarno sequence (SD, black) is accessible, allowing translation to initiate. On binding L7Ae the stem-loop forms, stabilized by protein-k-turn binding. The Shine-Dalgarno sequence is now incorporated into the C-helix of the k-turn and thus occluded so that translation cannot be initiated. 
structure consequent to the binding of L30e prevents the interaction with both the ribosome and U1 snRNA species.

Returning to the archaea, L7Ae has been shown to have multiple targets for regulation. In their RIP-Seq analysis of S. acidocaldarius, Daume et al. (2017) found that L7Ae also lowered translation of the structural gene for NOP5, another protein involved in the assembly of the box C/D snoRNP. In T. kodakarensis, a putative k-turn has been found in the mRNA of a bicistronic gene encoding the box C/D proteins NOP5 and fibrillarin (Jäger et al. 2014). These authors also identified a putative k-turn in the cbf5 gene that encodes the pseudouridinylase enzyme of the H/ACA snoRNP complex (Jäger et al. 2014). Thus, the assembly of archaeal snoRNP species is likely to be regulated by L7Ae at multiple points. We have also recently shown that a subset of human box C/D snoRNPs are subject to probable regulation by $\mathrm{N}^{6}$-methylation of adenine within the core of the k-turn structure (Huang et al. 2017). The k-turn structures of the snoRNPs appear to be a major locus for the control of assembly.

Thus, L7Ae binds to elements in the $5^{\prime}$-UTR in transcripts of multiple genes encoding proteins required in snoRNP assembly, including its own 17ae gene, altering the conformation of the RNA to modulate translation of the gene. These elements are genetic OFF switches that are mediated by a change in RNA conformation. They meet all the requirements for the definition of a riboswitch, except that most define a riboswitch as a motif in mRNA that responds to the binding of a small-molecule metabolite. Clearly a protein is not a small molecule, yet some authors consider the T-box element to be a riboswitch, despite the fact that its ligand is tRNA which is hardly a small metabolite. Whether or not this is considered to be a riboswitch is largely a question of definition, yet it conforms mechanistically to all the usual aspects of riboswitch function apart from the size of the ligand. The key aspect of the riboswitch mechanism in most cases is a ligand-induced change in RNA conformation, and that is what happens when L7Ae binds the k-turn. Yet however this is classified, the modulation of expression is mediated by protein-induced alteration of the RNA structure and represents an important mechanism of riboregulation.

\section{MATERIALS AND METHODS}

\section{RNA synthesis and deprotection}

RNA oligonucleotides were synthesized using the solid-phase phosphoramidite chemistry implemented on an ABI-394 DNA/ RNA synthesizer. The ribonucleotide phosphoramidites, Pac-A$\mathrm{CE}$, Ac-C-CE, iPr-Pac-G-CE, and U-CE, with a t-BDMS protecting group on the $2^{\prime} \mathrm{O}$, were obtained from Link Technologies. Fluorescein (Link Technologies) and Cy3 (GE Healthcare) were attached to the $5^{\prime}$ termini of the oligonucleotides as phosphoramidites in the final cycle of the synthesis, as required.
RNA oligonucleotides were deprotected in 25\% ethanol/ammonia solution for $3 \mathrm{~h}$ at room temperature and evaporated to dryness. They were redissolved in $115 \mu \mathrm{L}$ DMSO (SigmaAldrich) to which was added $60 \mu \mathrm{L}$ triethylamine (Sigma-Aldrich) and $75 \mu \mathrm{L} 1 \mathrm{M}$ triethylamine trihydrofluoride (Sigma-Aldrich), and incubated at $65^{\circ} \mathrm{C}$ for $2.5 \mathrm{~h}$ to remove the $t$-BDMS protecting groups. Thereafter, samples were cooled on ice for $10 \mathrm{~min}$ and $250 \mu \mathrm{L}$ RNA quenching buffer (Glen Research) was added to stop the reaction. The oligonucleotides were then desalted by application to NAP-10 columns (GE Healthcare).

\section{RNA purification and hybridization}

Oligoribonucleotides were purified by gel electrophoresis under denaturing conditions, using 20\% acrylamide: bis-acrylamide (19:1) (Scientific Laboratory Supplies) electrophoresed in $90 \mathrm{mM}$ Tris-borate ( $\mathrm{pH} 8.5), 10 \mathrm{mM}$ EDTA (TBE buffer) containing $7 \mathrm{M}$ urea at $25 \mathrm{~W}$ for $\sim 3 \mathrm{~h}$. Nucleic acids were visualized by UV shadowing and bands corresponding to full-length products were excised and electroeluted into $140 \mu \mathrm{L} 8 \mathrm{M}$ ammonium acetate in TBE at $150 \mathrm{~V}$ at room temperature. The RNA was then precipitated with ethanol.

Fluorophore-labeled RNA was subjected to further purification by reversed-phase HPLC on a C18 column (ACE 10-300, Advanced Chromatography Technologies), using an acetonitrile gradient with an aqueous phase of $100 \mathrm{mM}$ triethylammonium acetate ( $\mathrm{pH}$ 7.0) (Fisher Scientific). Peak fractions were evaporated to dryness and resuspended in $120 \mu \mathrm{L}$ ultrapure water.

For FRET experiments, duplex species were prepared by mixing equimolar quantities of oligoribonucleotides and annealing in $90 \mathrm{mM}$ Tris-borate (pH 8.5), $10 \mathrm{mM}$ EDTA, and $25 \mathrm{mM} \mathrm{NaCl}$ by slow cooling from $95^{\circ} \mathrm{C}$ to $4^{\circ} \mathrm{C}$. Hybridized RNA was purified by gel electrophoresis under nondenaturing conditions in $12 \%$ acrylamide: bis-acrylamide (29:1), in TBE, $25 \mathrm{mM} \mathrm{NaCl}$, with buffer recirculation. Electrophoresis was performed at $150 \mathrm{~V}$ at $4^{\circ} \mathrm{C}$ for $\sim 6 \mathrm{~h}$. Bands containing duplex RNA were excised from the gel and electroeluted into $140 \mu \mathrm{L} 8 \mathrm{M}$ ammonium acetate in TBE at $100 \mathrm{~V}$ at $4{ }^{\circ} \mathrm{C}$, followed by ethanol precipitation and air-drying at $4^{\circ} \mathrm{C}$.

\section{L7Ae expression and purification}

A. fulgidus L7Ae cloned into a modified pET-Duet1 plasmid (Novagen) (Huang et al. 2011) was expressed as a hexahistidine fusion protein in Escherichia coli BL21-Gold (DE3) pLysS cells (Stratagene), and purified as reported previously (Huang and Lilley 2013).

\section{Steady-state FRET analysis of RNA folding}

FRET experiments were performed using a duplex RNA species, terminally $5^{\prime}$-labeled with fluorescein on the bulged strand and Cy3 on the nonbulged strand, containing a central I7Ae 5'-UTR element k-turn sequence (Fig. 2). The strands used to prepare the duplex RNA species were (all sequences written $5^{\prime}-3^{\prime}$ ): FluCCAGUCAGGGCCGAUGAAUGAGUUCAGG and Cy3-CCUG AACUCAUGAAGCCCUGACUGG; when hybridized together these generated a C-helix of $12 \mathrm{bp}$, and an NC-helix of $13 \mathrm{bp}$. The absorption spectrum was measured by resuspending the 
ethanol precipitated hybrid RNA in $120 \mu \mathrm{L} 90 \mathrm{mM}$ Tris-borate $(\mathrm{pH}$ 8.4) and recording the absorbance in a $50 \mathrm{~mm}$ path length cuvette using a NanoDrop 2000c spectrophotometer (Thermo Scientific). The spectrum was deconvoluted using corresponding RNA species labeled only with $\mathrm{Cy} 3$, and fluorophore absorption ratios calculated using a MATLAB program. Fluorescence spectra were recorded in $90 \mathrm{mM}$ Tris-borate $(\mathrm{pH} 8.4)$ at $4^{\circ} \mathrm{C}$ using an SLMAminco 8100 fluorimeter. The spectra were corrected for lamp fluctuations and instrumental variations, and polarization artifacts were avoided by crossing excitation and emission polarizers at $54.7^{\circ}$. Values of FRET efficiency were measured using the acceptor normalization method (Clegg 1992) implemented in MATLAB. $E_{\text {FRET }}$ as a function of L7Ae concentration was fitted to

$$
\begin{aligned}
& E_{\text {FRET }}=E_{0}+\Delta E_{\text {FRET }} . \\
& \frac{\left(1+K_{A} P_{T}+K_{A} R_{T}\right)-\sqrt{\left(1+K_{A} P_{T}+K_{A} R_{T}\right)^{2}-4 R_{T} K_{A}^{2} P_{T}}}{2 R_{T} K_{A}}
\end{aligned}
$$

where $E_{0}$ is the initial FRET efficiency in the absence of added protein, $\Delta E_{\mathrm{FRET}}$ is the full range of the change in FRET efficiency, $K_{A}$ is the apparent association constant, and $P_{T}$ and $R_{T}$ are the total concentration of L7Ae and RNA, respectively.

\section{Crystallization, structure determination, and refinement}

A solution of $0.6 \mathrm{mM}$ RNA (19 nt) and $0.6 \mathrm{mM}$ L7Ae in $5 \mathrm{mM}$ Tris$\mathrm{HCl}(\mathrm{pH} 8.0), 100 \mathrm{mM} \mathrm{NaCl}, 10 \mathrm{mM} \mathrm{MgCl} 2$ was incubated for $1 \mathrm{~min}$ at $85^{\circ} \mathrm{C}$. Crystals were grown by vapor diffusion using drops prepared by mixing $1.0 \mu \mathrm{L}$ of the RNA-protein complex with $1 \mu \mathrm{L}$ of a reservoir solution comprising $0.01 \mathrm{M} \mathrm{Mg}$ acetate, $0.05 \mathrm{M} \mathrm{MES}$ $\mathrm{pH} 5.6$, and $2.5 \mathrm{M}$ ammonium sulfate at $7^{\circ} \mathrm{C}$. Crystals appeared after $5 \mathrm{~d}$. They were transferred into reservoir solution containing $30 \%$ glycerol for $\sim 3 \mathrm{sec}$. The crystals were flash frozen by mounting in nylon loops and plunging into liquid nitrogen. The crystals were characterized in-house with a MicroMax HF007 copper rotating anode $\mathrm{X}$-ray generator equipped with an ACTOR sample changer system and a Saturn $944 \mathrm{HG}+$ CCD detector (Rigaku). Suitable samples were stored and subsequently used to measure full data sets on beamline I03 of Diamond Light Source (Harwell). Data were processed by XIA2 (Winter et al. 2018). The resolution cutoff for the data was determined by examining by $\mathrm{CC} 1 / 2$ and density map as described previously (Karplus and Diederichs 2012). The crystals had space group 1422 and unit cell dimensions $a=142.1 \AA, b=142.1 \AA, c=166.8 \AA$. From crystal density considerations (Matthews 1968; Kantardjieff and Rupp 2003), one and a half RNA-protein complexes were expected to be present in the asymmetric unit.

The structure was determined by molecular replacement using the k-turn L7Ae complex model extracted from PDB 4BW0. The resulting electron density maps revealed the remaining RNA density and were built de novo on the basis of the difference map. Structural models were built in Coot (Emsley et al. 2010) and refined by Phenix (Adams et al. 2010). Omit maps were calculated using Phenix. Ramachandran analysis shows that $99.7 \%$ of amino acid residues are in the most favored and additionally allowed regions. Model geometry and the fit to electron-density maps were monitored with MOLPROBITY (Chen et al. 2010) and the valida- tion tools in COOT. Atomic coordinates and structure factor amplitudes have been deposited with the PDB with accession code $6 \mathrm{HCT}$.

\section{Analysis of L7Ae binding by in-line probing}

In-line probing assays were performed as previously described (Soukup and Breaker 1999; Regulski and Breaker 2008). A total of $20 \mu \mathrm{L}$ volumes of 100 pmol of $5^{\prime}$-Cy5-labeled RNA in $50 \mathrm{mM}$ Tris- $\mathrm{HCl}\left(\mathrm{pH} 8.3\right.$ at $\left.20^{\circ} \mathrm{C}\right), 20 \mathrm{mM} \mathrm{MgCl} 2,100 \mathrm{mM} \mathrm{KCl}$ were supplemented with $2.5-10 \mu \mathrm{M}$ L7Ae where required. RNA was folded by exposure to $85^{\circ} \mathrm{C}$ for $1 \mathrm{~min}$ followed by slow cooling to $20^{\circ} \mathrm{C}$. Samples were then incubated at $20^{\circ} \mathrm{C}$ for $40 \mathrm{~h}$, after which gel electrophoresis loading buffer containing $7 \mathrm{M}$ urea, $10 \mathrm{mM}$ EDTA was added. Partial alkaline digest was performed by incubation of 100 pmol of Cy5-labeled RNA in $20 \mu \mathrm{L} 50 \mathrm{mM}$ $\mathrm{Na}_{2} \mathrm{CO}_{3}$ buffer $\left(\mathrm{pH} 9.0\right.$ at $20^{\circ} \mathrm{C}$ ) at $90^{\circ} \mathrm{C}$ for $10 \mathrm{~min}$. The reaction was terminated by addition of gel loading buffer at $0^{\circ} \mathrm{C}$. Each Cy5-labeled RNA was subjected to cleavage by RNase T1. 100 pmol of RNA was incubated with $5 \mathrm{U}$ RNase T1 in $10 \mu \mathrm{L} 25 \mathrm{mM}$ sodium citrate buffer $\left(\mathrm{pH} 5.0\right.$ at $\left.20^{\circ} \mathrm{C}\right)$ containing $5 \mathrm{M}$ urea, $0.5 \mathrm{mM}$ EDTA for $10 \mathrm{~min}$ at $55^{\circ} \mathrm{C}$. The reaction was terminated by addition of gel loading buffer. Samples were electrophoresed in a $20 \%$ polyacrylamide gel containing $7 \mathrm{M}$ urea. RNA was visualized by using a Typhoon FLA 9500 fluorimager (GE Healthcare).

\section{DATA DEPOSITION}

Coordinates have been deposited in the Protein Data Bank with accession code 6HCT.

\section{SUPPLEMENTAL MATERIAL}

Supplemental material is available for this article.

\section{ACKNOWLEDGMENTS}

We thank Dr. Timothy Wilson for discussion, and Cancer Research UK for financial support (program grant A18604).

Received August 23, 2018; accepted October 7, 2018.

\section{REFERENCES}

Adams PD, Afonine PV, Bunkoczi G, Chen VB, Davis IW, Echols N, Headd JJ, Hung LW, Kapral GJ, Grosse-Kunstleve RW, et al. 2010. PHENIX: a comprehensive Python-based system for macromolecular structure solution. Acta Crystallogr D Biol Crystallog 66: 213-221. doi:10.1107/S0907444909052925

Ashraf S, Huang L, Lilley DMJ. 2017. Sequence determinants of the folding properties of box C/D kink-turns in RNA. RNA 23: 1927-1935. doi:10.1261/rna.063453.117

Ban N, Nissen P, Hansen J, Moore PB, Steitz TA. 2000. The complete atomic structure of the large ribosomal subunit at $2.4 \AA$ resolution. Science 289: 905-920. doi:10.1126/science.289.5481.905

Battistuzzi FU, Feijao A, Hedges SB. 2004. A genomic timescale of prokaryote evolution: insights into the origin of methanogenesis, phototrophy, and the colonization of land. BMC Evol Biol 4: 44. doi:10.1186/1471-2148-4-44 
Chao JA, Williamson JR. 2004. Joint X-ray and NMR refinement of the yeast L30e-mRNA complex. Structure 12: 1165-1176. doi:10.1016/j.str.2004.04.023

Chen VB, Arendall WB 3rd, Headd JJ, Keedy DA, Immormino RM, Kapral GJ, Murray LW, Richardson JS, Richardson DC. 2010. MolProbity: all-atom structure validation for macromolecular crystallography. Acta Crystallogr D Biol Crystallogr 66: 12-21. doi:10.1107/S0907444909042073

Cho IM, Lai LB, Susanti D, Mukhopadhyay B, Gopalan V. 2010. Ribosomal protein $L 7 A e$ is a subunit of archaeal RNase P. Proc Natl Acad Sci 107: 14573-14578. doi:10.1073/pnas.1005556107

Clegg RM. 1992. Fluorescence resonance energy transfer and nucleic acids. Methods Enzymol 211: 353-388. doi:10.1016/0076-6879 (92)11020-J

Dabeva MD, Warner JR. 1993. Ribosomal protein L32 of Saccharomyces cerevisiae regulates both splicing and translation of its own transcript. J Biol Chem 268: 19669-19674.

Daldrop P, Lilley DMJ. 2013. The plasticity of a structural motif in RNA: structural polymorphism of a kink turn as a function of its environment. RNA 19: 357-364. doi:10.1261/rna.036657.112

Daume M, Uhl M, Backofen R, Randau L. 2017. RIP-seq suggests translational regulation by L7Ae in Archaea. MBio 8: e00730-17. doi:10.1128/mBio.00730-17

Emsley P, Lohkamp B, Scott WG, Cowtan K. 2010. Features and development of Coot. Acta Crystallogr D Biol Crystallogr 66: 486-501. doi:10.1107/S0907444910007493

Eng FJ, Warner JR. 1991. Structural basis for the regulation of splicing of a yeast messenger RNA. Cell 65: 797-804. doi:10.1016/00928674(91)90387-E

Goody TA, Melcher SE, Norman DG, Lilley DMJ. 2004. The kink-turn motif in RNA is dimorphic, and metal ion dependent. RNA 10: 254-264. doi:10.1261/rna.5176604

Hamma T, Ferré-D'Amaré AR. 2004. Structure of protein L7Ae bound to a K-turn derived from an archaeal box H/ACA sRNA at $1.8 \AA \AA$ resolution. Structure 12: 893-903. doi:10.1016/j.str.2004.03.015

Huang L, Lilley DMJ. 2013. The molecular recognition of kink turn structure by the L7Ae class of proteins. RNA 19: 1703-1710. doi:10.1261/rna.041517.113

Huang L, Lilley DMJ. 2018. The kink-turn in the structural biology of RNA. Q Rev Biophys 51: 1-32. doi:10.1017/S0033583518000033

Huang L, Yin P, Zhu X, Zhang Y, Ye K. 2011. Crystal structure and centromere binding of the plasmid segregation protein ParB from pCXC100. Nucleic Acids Res 39: 2954-2968. doi:10.1093/nar/ gkq915

Huang L, Wang J, Lilley DMJ. 2016. A critical base pair in k-turns determines the conformational class adopted, and correlates with biological function. Nucleic Acids Res 44: 5390-5398. doi:10.1093/ nar/gkw201

Huang L, Ashraf S, Wang J, Lilley DMJ. 2017. Control of box C/D snoRNP assembly by $N^{6}$-methylation of adenine. EMBO Rep 18: 1631-1645. doi:10.15252/embr.201743967

Jäger D, Förstner KU, Sharma CM, Santangelo TJ, Reeve JN. 2014. Primary transcriptome map of the hyperthermophilic archaeon Thermococcus kodakarensis. BMC Genomics 15: 684. doi:10.1186/1471-2164-15-684

Kantardjieff KA, Rupp B. 2003. Matthews coefficient probabilities: improved estimates for unit cell contents of proteins, DNA, and protein-nucleic acid complex crystals. Protein Sci 12: 1865-1871. doi:10.1110/ps.0350503

Karplus PA, Diederichs K. 2012. Linking crystallographic model and data quality. Science 336: 1030-1033. doi:10.1126/science. 1218231

Klein DJ, Schmeing TM, Moore PB, Steitz TA. 2001. The kink-turn: a new RNA secondary structure motif. EMBO J 20: 4214-4221. doi:10.1093/emboj/20.15.4214
Koonin EV, Bork P, Sander C. 1994. A novel RNA-binding motif in omnipotent suppressors of translation termination, ribosomal proteins and a ribosome modification enzyme? Nucleic Acids Res 22: 2166-2167. doi:10.1093/nar/22.11.2166

Kuhn JF, Tran EJ, Maxwell ES. 2002. Archaeal ribosomal protein L7 is a functional homolog of the eukaryotic $15.5 \mathrm{kD} /$ Snu13p snoRNP core protein. Nucleic Acids Res 30: 931-941. doi:10.1093/nar/ 30.4 .931

Lescoute A, Leontis NB, Massire C, Westhof E. 2005. Recurrent structural RNA motifs, isostericity matrices and sequence alignments. Nucleic Acids Res 33: 2395-2409. doi:10.1093/nar/gki535

Li L, Ye K. 2006. Crystal structure of an H/ACA box ribonucleoprotein particle. Nature 443: 302-307. doi:10.1038/nature05151

Liu J, Lilley DMJ. 2007. The role of specific 2'-hydroxyl groups in the stabilization of the folded conformation of kink-turn RNA. RNA 13: 200-210. doi:10.1261/rna.285707

Mao H, White SA, Williamson JR. 1999. A novel loop-loop recognition motif in the yeast ribosomal protein L30 autoregulatory RNA complex. Nat Struct Biol 6: 1139-1147. doi:10.1038/70081

Marmier-Gourrier N, Cléry A, Senty-Ségault V, Charpentier B, Schlotter F, Leclerc F, Fournier R, Branlant C. 2003. A structural, phylogenetic, and functional study of $15.5-\mathrm{kD} /$ Snu13 protein binding on U3 small nucleolar RNA. RNA 9: 821-838. doi:10. 1261/rna.2130503

Matthews BW. 1968. Solvent content of protein crystals. J Mol Biol 33: 491-497. doi:10.1016/0022-2836(68)90205-2

McPhee SA, Huang L, Lilley DMJ. 2014. A critical base pair in k-turns that confers folding characteristics and correlates with biological function. Nat Commun 5: 5127. doi:10.1038/ncomms6127

Moore T, Zhang Y, Fenley MO, Li H. 2004. Molecular basis of box C/D RNA-protein interactions; cocrystal structure of archaeal L7Ae and a box C/D RNA. Structure 12: 807-818. doi:10.1016/ j.str.2004.02.033

Nottrott S, Hartmuth K, Fabrizio P, Urlaub H, Vidovic I, Ficner R, Lührmann R. 1999. Functional interaction of a novel 15.5kD [U4/ U6.U5] tri-snRNP protein with the $5^{\prime}$ stem-loop of U4 snRNA. EMBO J 18: 6119-6133. doi:10.1093/emboj/18.21.6119

Pogacić V, Dragon F, Filipowicz W. 2000. Human H/ACA small nucleolar RNPs and telomerase share evolutionarily conserved proteins NHP2 and NOP10. Mol Cell Biol 20: 9028-9040. doi:10.1128/ MCB.20.23.9028-9040.2000

Regulski EE, Breaker RR. 2008. In-line probing analysis of riboswitches. Methods Mol Biol 419: 53-67. doi:10.1007/978-159745-033-1_4

Rozhdestvensky TS, Tang TH, Tchirkova IV, Brosius J, Bachellerie J-P, Hüttenhofer A. 2003. Binding of L7Ae protein to the K-turn of archaeal snoRNAs: a shared RNA binding motif for C/D and H/ACA box snoRNAs in Archaea. Nucleic Acids Res 31: 869-877. doi:10.1093/nar/gkg175

Serganov A, Polonskaia A, Ehresmann B, Ehresmann C, Patel DJ. 2003. Ribosomal protein $\mathrm{S} 15$ represses its own translation via adaptation of an rRNA-like fold within its mRNA. EMBO J 22: 1898-1908. doi:10.1093/emboj/cdg170

Soukup GA, Breaker RR. 1999. Relationship between internucleotide linkage geometry and the stability of RNA. RNA 5: 1308-1325. doi:10.1017/S1355838299990891

Szewczak LB, DeGregorio SJ, Strobel SA, Steitz JA. 2002. Exclusive interaction of the $15.5 \mathrm{kD}$ protein with the terminal box C/D motif of a methylation guide snoRNP. Chem Biol 9: 1095-1107. doi:10.1016/S1074-5521(02)00239-9

Turner B, Lilley DMJ. 2008. The importance of G.A hydrogen bonding in the metal ion- and protein-induced folding of a kink turn RNA. J Mol Biol 381: 431-442. doi:10.1016/j.jmb.2008. 05.052 
Turner B, Melcher SE, Wilson TJ, Norman DG, Lilley DMJ. 2005. Induced fit of RNA on binding the L7Ae protein to the kink-turn motif. RNA 11: 1192-1200. doi:10.1261/rna.2680605

Vidovic I, Nottrott S, Hartmuth K, Lührmann R, Ficner R. 2000. Crystal structure of the spliceosomal $15.5 \mathrm{kD}$ protein bound to a U4 snRNA fragment. Mol Cell 6: 1331-1342. doi:10.1016/S10972765(00)00131-3

Wang J, Fessl T, Schroeder KT, Ouellet J, Liu Y, Freeman AD, Lilley DMJ. 2012. Single-molecule observation of the induction of k-turn RNA structure on binding L7Ae protein. Biophys J 103: 2541-2548. doi:10.1016/j.bpj.2012.11.006

Watkins NJ, Segault V, Charpentier B, Nottrott S, Fabrizio P, Bachi A, Wilm M, Rosbash M, Branlant C, Lührmann R. 2000. A common core RNP structure shared between the small nucleolar box C/D RNPs and the spliceosomal U4 snRNP. Cell 103: 457-466. doi:10.1016/S0092-8674(00)00137-9

Watkins NJ, Dickmanns A, Lührmann R. 2002. Conserved stem II of the box C/D motif is essential for nucleolar localization and is required, along with the $15.5 \mathrm{~K}$ protein, for the hierarchical assembly of the box C/D snoRNP. Mol Cell Biol 22: 8342-8352. doi:10.1128/MCB.22.23.8342-8352.2002

Winter G, Waterman DG, Parkhurst JM, Brewster AS, Gildea RJ, Gerstel M, Fuentes-Montero L, Vollmar M, Michels-Clark T, Young ID, et al. 2018. DIALS: implementation and evaluation of a new integration package. Acta Crystallogr D Struct Biol 74: 85-97. doi:10.1107/S2059798317017235 

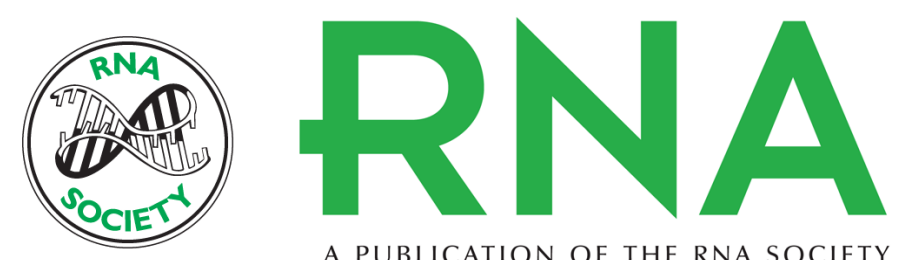

A PUBLICATION OF THE RNA SOCIETY

\section{The role of RNA structure in translational regulation by L7Ae protein in archaea}

Lin Huang, Saira Ashraf and David M.J. Lilley

RNA 2019 25: 60-69 originally published online October 16, 2018

Access the most recent version at doi:10.1261/rna.068510.118

\section{Supplemental http://rnajournal.cshlp.org/content/suppl/2018/10/16/rna.068510.118.DC1 Material}

References This article cites 48 articles, 17 of which can be accessed free at: http://rnajournal.cshlp.org/content/25/1/60.full.html\#ref-list-1

Open Access Freely available online through the RNA Open Access option.

Creative This article, published in $R N A$, is available under a Creative Commons License Commons (Attribution 4.0 International), as described at

License http://creativecommons.org/licenses/by/4.0/.

Email Alerting Receive free email alerts when new articles cite this article - sign up in the box at the Service top right corner of the article or click here. 